\title{
Stakeholder role in tourism sustainability: the case of Kwame Nkrumah Mausoleum and centre for art and culture in Ghana
}

George Kofi Amoako

Marketing, University of Professional Studies Accra Ghana, Accra, Ghana

Theresa Obuobisa-Darko

Human Resource, Methodist University College Ghana, Accra, Ghana, and

Sylvia Ohene Marfo

Department of Sociology, University of Ghana, Accra, Ghana

\begin{abstract}
Purpose - The paper examines the role of stakeholders in tourism and hospitality industry to ensure sustainability. This study focuses on investigating how stakeholders view can influence business sustainability in the tourism industry in Ghana and Africa. The study also looks at the future of sustainable tourism activities in Ghana and Africa.

Design/methodology/approach - A qualitative approach was adopted and interviewees were purposively selected. Using the semi-structured interview 12 people were interviewed and NVivo used to analyse the data. The study was carried out in Accra the capital city of Ghana. Using the stakeholder based theory and resource based theory (RBT) the study addresses how sustainable competitive advantage can be developed.

Findings - Results shows how stakeholders involved such employees, government, community/society, private sector and individual shop owners perceive factors that enhance or limit progress in tourism. Some challenges they encounter include high level of illiteracy, lack of education for upcoming youth, low funding and publicity, lack of the enforcement of laws in the sector. The findings also indicated that to ensure sustainability in the industry the products should be unique, valuable, rare, non-substitutable and non-imitable and has to be advertised.

Research limitations/implications - Researchers encountered difficulties in eliciting answers from stakeholders who are experts and managers in the industry because of their busy schedules. The researcher admits that this research work which is carried out only in Ghana cannot be used to generalise an assumption for the entire industry sectors in Africa and beyond. The sample size could be improved and the study could be conducted in other African countries for the purposes of comparison.

Practical implications - This study reveals how stakeholders view developments in the tourism sector and this can be used as a guide in developing policies and marketing strategies in the tourism industry. Both theoretical and managerial implications are discussed.

Originality/value - Very little literature has been written on stakeholders' view on business sustainability in the tourism industry in Ghana. Moreover the use of stakeholder and resource based view theories application in developing competitive advantage in the developing country perspective is unique. The findings in no small way will somehow benefit the government and industry stakeholders by providing the latest views and perspectives in Ghana.
\end{abstract}

Keywords Tourism, Stakeholder, Sustainability, Sustainable tourism

Paper type Research paper

(C) George Kofi Amoako, Theresa Obuobisa-Darko and Sylvia Ohene Marfo. Published in International Hospitality Review Published by Emerald Publishing Limited. This article is published under the Creative Commons Attribution (CC BY 4.0) licence. Anyone may reproduce, distribute, translate and create derivative works of this article (for both commercial and non-commercial purposes), subject to full attribution to the original publication and authors. The full terms of this licence may be seen at http:// creativecommons.org/licences/by/4.0/legalcode

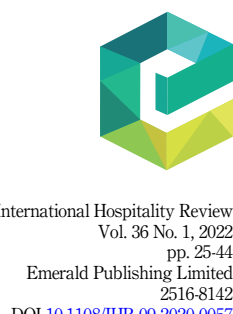

DOI 10.1108/IHR-09-2020-0057 
IHR

36,1

\section{Introduction}

Competition has become a common issue in the tourism industry, one of the world's largest industries, which been experiencing constant rapid annual increase in revenue and employment (Pırnar and Günlü, 2012). With such dynamic competition in the market, only tourism destinations that employ strategies that can attract tourists coupled with effective management and marketing can thrive. Stakeholders' activities have major impact on tourism destinations' success or failure and as such, managers of tourism destination sites must have interest in stakeholder management whiles ensuring sustainable competitive advantage at the same time. The focal point in this research stream is how to manage stakeholders' interest whiles ensuring profitability for both public and private sector tourism and hospitality participants. The hospitality industry which comprises hotels, food and beverages and tourism subsectors is a key component of Ghana's economy. The industry is the fourth highest foreign exchange earner for Ghana after gold, cocoa and more recently oil, contributing some 7.1\% to the country's gross domestic product (GDP) in 2017 (PwC, 2017). The tourism sector therefore holds a great potential to both government and private sector investors in Ghana. A review of the literature showed that not many studies have been carried out in the area of stakeholder role in sustainable tourism within the Ghanaian context using the qualitative method and therefore the need to fill this methodological and context gap. This study is aimed at outlining the roles stakeholders play in sustainable tourism in the country as well as identifying some of the challenges in developing sustainable competitive advantage for the selected tourist sites from stakeholders' perspective and how to overcome them using the limited resources available. The question then is "What is the role of stakeholders in ensuring sustainability in the tourism industry? Studying stakeholder roles in ensuring sustainable tourism is important and timely as Ghana has initiated its Marine Drive Tourism Project, which aims at developing the coastline of the country particularly in the capital, Accra. This project is expected to provide employment and revenue as well as employment opportunities for stakeholders. The study areas selected for this study fall in the area demarcated for this project and provide the opportunity to explore the expectations of stakeholders regarding the tourism industry in relation to ensuring sustainable tourism and competitive advantage. The paper is divided into seven sections. This introduction is followed by a literature review as well as the theory that underlines the study. This is followed by the methods used in collecting and analysing the data and discuss of the findings. The theoretical and managerial implications of this study are discussed in sections five and six, after which we draw a conclusion from our discussions.

\section{Literature review}

Tourism is defined as "the processes, activities, and outcomes arising from the relationships and the interactions among tourists, tourism suppliers, host governments, host communities, and surrounding environments that are involved in the attracting and hosting of visitors" (Goeldner and Ritchie, 2005, p. 5). This process according to them involves different activities, services and industries that provide different experience such as transportation, accommodations, eating and drinking establishments, shops, entertainment and other hospitality services which are available for individuals or groups that are travelling away from home. This section explains stakeholder as a concept and describes the theories used for the paper. It then ends on information on sustainable tourism development.

\section{Definition of stakeholder and theories}

For tourism to be sustainable, all stakeholders must be involved. Freeman (1984, p. 46) defines stakeholder as "any group or individual who can affect or is affected by the achievement or 
the organisation's objectives". Four main stakeholders who play roles in tourism development according to Goeldner and Ritchie (2005) are the tourist, the business providing tourist goods and services, which is entrepreneur, the government of the host community or area and the host community, that is, the residents. Each of these stakeholders is critical towards the successful tourism activities.

Tourism is a social, cultural and economic issue which involves the movement of people to different places outside their usual environment for personal, business or professional purposes (United Nations World Tourism Organization, 2008). Thus, a tourist is "someone who travels at least $80 \mathrm{~km}$ from his or her home for at least 24 hours, for business or leisure or other reasons" (LinkBC, 2008, p. 8). The entrepreneur sees tourism as an opportunity to make profit via providing goods and services that the tourist is interested. The host community includes the local people who consider tourism as cultural and avenue for employment. The local government includes the politicians who view tourism as "a wealth factor in the economy of their jurisdiction" (Goeldner and Ritchie, 2005). They formulate policies and implement them to ensure it serves this purpose. Even though all these stakeholders are involved one way or the other in decision making and sustenance of the tourist industry, their involvement is not equal (Byrd, 2007; UNEP, 2005). For instance, the UNEP (2005) have suggested that the government has to take the leading role. This is so because the tourist industry is very fragmented, sustainability relates to areas of public concern and lastly, the government has many of the tools that can be used to make the difference (UNEP, 2005).

\section{Stakeholder based theory}

This paper used the stakeholder based theory which has achieved popularity among both academics and non-academics. It is described as a comprehensive approach (Harrison et al., 2015) that explains and guides the structure and operations of established corporations (Donaldson and Preston, 1995). Stakeholder based theory is a practical theory that has its beginning in organisational management and ethics and it is distinct from others because it addresses morals and values explicitly as a central feature of managing organisations (Philips et al., 2003). Thus, it is a management theory based on moral treatment of stakeholders (Harrison et al., 2015) and a practical theory because all firms have stakeholders who have to be managed.

Donaldson and Preston (1995) outlined three components of this theory: descriptive accuracy, instrumental power and normative validity aspect. The descriptive accuracy describes the past, present and future state of the organisation and their stakeholders (Donaldson and Preston, 1995). Relating to tourism, one can examine the organisation, its history and how it has influenced its present and will impact the future. Instrumental power emphasises the link between actions in stakeholder management and the resulting outcomes. Linked to tourism, it could be the emergence of a competitor and how this will result in the redistribution of the market share. Thus, in this study we focus on how the various stakeholders in the tourist industry are managed to ensure sustainable tourism development. The normative aspect of the theory, the fundamental core of the theory is used to "interpret the functions of the corporation, including the identification of moral or philosophical guidelines for the operations and management of the corporation" (Donaldson and Preston, 1995, p. 71). Thus, it explains the logic behind an organisation and other stakeholders taking part in an activity as the right thing to do (Byrd, 2007). Based on this assumption, it is necessary that stakeholders participate in determining the direction of the organisation in which they have a stake. Managers of organisation should consciously try to involve all stakeholders, appreciate and understand their interest, since those subordinates who perceive they are being neglected will leave, which might have a negative impact on sustaining its development. 
IHR

36,1

\section{Resource based theory}

One of the most common theories used to study the performance of organisations is the resource based theory (RBT). The RBT foci are that a business's internal resources, especially differentiated employee competencies, can be its direct source of sustained competitive advantage (Davis and Simpson, 2017). This implies not only resources but capabilities defined as an organisation's capacity to deploy resources (Amit and Schoemaker, 1993) are potential sources of an organisation's sustained competitive advantage. An organisation is described as having a sustained competitive advantage when its competitors cannot imitate its main strategy and as such replicate the advantages of using that strategy (Della, et al., 2012). The theory, according to Barney (1991), has two basic assumptions: first, the strategic resource each firm can command in the same industry or group is dissimilar, which leads to difference among these firms; second, these distinctions among the firms are not easy to be imitated.

Resources can be broadly explained to include assets, organisational processes, business attributes, information or the knowledge an organisation controls which can be used to develop strategies and/or help implementation of the strategies (Madhani, 2010). These resources of the organisation have been categorised into three: physical capital resources including physical, technological, plant and equipment; human capital resources comprising training, experience and insight and organisational capital resources which involves the formal structure (Barney, 1991).

Barney further maintains that resources and capabilities can be regarded as having competitive advantage if only they are valuable (V), rare (R), imitable (I) and non-substitutable $(\mathrm{N})$. This is described in the literature as the "VRIN" criteria of a resource. Thus, an organisation cannot have a competitive advantage when the resources in the organisation do not fulfil these criteria. This is so because the organisation uses these resources and competencies to develop and implement their strategies. The estimation of the value of a resource can be the value the firm is able to attain in market exchange (Bowman and Ambrosini, 2000).

According to Madhani (2010) a resource is valuable "if it provides strategic value to the firm" (p. 5). Thus, the resource must help the firm conceive and implement strategies that enhance efficiency and effectiveness (Barney, 1991). The other three components are what Fahy (2000) describes as the barriers to duplication, i.e. rarity, imitability and non-substitutability. The resource of an organisation should be rare. That is, it should be difficult for both existing and potential competitors to discover (Madhani, 2010). An organisation cannot have a competitive advantage when the resources they have are in abundance and accessible to most organisations in an industry. The third criterion is the resource must be imitable. Madhani (2010) describes an imitable resource as one that cannot be copied. Thus, such a resource is impossible to imitate perfectly. Non-substitutability describes a resource that cannot be substituted with any alternate resource. The implication of this theory for the businesses in tourist industry is that, for these businesses to continue to enjoy sustained competitive advantage, there is the need to identify their resources and competencies and ensure the resources available to them have the VRIN characteristics. VRIN has been accepted as a technique which helps identify the usefulness of a resource with a sustained competitive advantage generation capacity (Barney, 1991). As a result, this paper attempts to identify the resources the tourist sites have, if they meet the VRIN criteria and whether its availability can facilitate the organisations or tourist sites to have a sustained competitive advantage.

\section{Sustainable tourism development}

At the heart of the concept of sustainable development lies the idea that any human activity, including tourism, should be undertaken in a way that the activity performed and the 
products produced provide a net positive long-term contribution to human and ecosystem wellbeing (ICMM, 2012). "Declaration of 2017 as the International Year of Sustainable Tourism and adoption of the Sustainable Development Goals (SDGs) have seemingly brought tourism to the forefront of development even where the SDGs have limited tourism focus" Musavengane et al. (2019). Both academics and non-academics have often used the term "sustainable development" in the past decade, yet scholars have not come to agree on its meaning (Sharpley, 2000). For instance, the Brundtland Commission defined sustainable development as "development that meets the needs of the present without compromising the ability for future generations to meet their own needs" (WCED, 1987, p. 43). This means that the actions or inactions of people now have far-reaching implications for the future. Boachie (2012) defined sustainable development as the combination of enhanced socio-economic growth and development, improved environmental protection and pollution prevention. This definition reflects an attempt to combine growing concerns about a range of environmental issues with socio-economic issues as Hopwood et al. (2005) suggested.

The concept of sustainable development, according to Hopwood et al. (2005), came as a result of the increase in the awareness of the global links between escalating environmental problems, socio-economic issues like poverty and concerns about a healthy future for humanity. The explanations and focus of sustainable development confirm that sustainable development is concerned with needs and wants of the present as well as the future generation focussing on the wellbeing of both generations in relation to the social, economic and environmental aspects. Using Ghana as an example, Domfeh et al. (2012) emphasised that having all these ideas on paper does not mean the achievement of the goals and that the sustainable development of Ghana could be a passing fad if issues confronting the country's sustainability are not addressed.

In the field of tourism, UNEP (2005) explained sustainable tourism as tourism that takes full account of its current and future economic, social and environmental impacts, addressing the needs of visitors, the industry, the environment and host communities. It added that sustainable tourism should therefore make the best use of environmental resources, respect host communities, ensure viable, long-term economic operations and provide benefits that are fairly distributed among all stakeholders. Butler (1999) explained sustainable tourism is one that respects the environment and as a consequence does not aid its own disappearance. Organisations that focus on tourism are seen to act sustainably when they consider the impact of their activities on the current economic, social and environmental dimensions of the community/country they operate within. Some challenges are encountered in attempt to ensure sustainable tourism. These include management of dynamic growth, change in climate, poverty alleviation, support for conservation and lastly health, safety and security (UNEP, 2005).

Researchers have suggested that sustainable tourism needs to focus on both the sustainable growth of tourism's contribution to the economy and the society at large as well as the sustainable use of resources and the environment based on the analysis of the demands of tourism (Liu et al., 2010; Butler, 1999). It is therefore imperative that tourist ensure that their actions contribute to the economy and the sustenance of both material and non-material resources within the environment they operate. Bramwell et al. (2008) have advocated that there should be a balance between growth of tourism and sustainability business issues arguing that tourism must be managed for sustainability including limiting its growth. More recent research has supported this view (Korstanje and George, 2020; Higgins-Desbiolles et al., 2019; Musavengane et al., 2020)

\section{Building sustainable competitive advantage}

Sustainable competitive advantage is required for a company to thrive in today's global environment and tourist sites are no exception. Sustainable competitive advantage refers to
Stakeholder role in tourism sustainability 
IHR

36,1

an organisation's assets, abilities, capabilities that are difficult to replicate and provide a better position over competitors.

Different models have been suggested to ensure an organisation is at a competitive advantage and one of such is the SWOT (strength, weakness, opportunity, threat) analysis. Aside the SWOT, Collins (2001) suggests that to build a sustainable competitive advantage tourist sites could aim at having disciplined people, disciplined thought and disciplined actions. He further broke these into six key concepts which are Level 5 leadership; first "who" then "what"; confront the true facts; Hedgehog concept; culture of discipline; and lastly, technology accelerator. Moreover, Mkwizu (2020) suggested that digital media, online presence and content and mobile advertising are among the trends in digital marketing that affords Africa the opportunity to market its attractions to tourists in this digital era.

Leadership refers to "the ability to influence a group toward the achievement of a vision or set goals" (Robbins and Judge, 2009, p. 410) which has different levels. Level 5 leaders have a mix of professional will and personal humility. They are intelligent because the managers' high intellectual level positively affects financial performance (Sami and Mohamed, 2014). Also, such leaders achieve results no matter how difficult it is and take responsibility for poor results not blaming other people. They are also quiet and calm, rely mainly on inspired standards and possess the charisma to motivate. The second is to ensure the organisation get the right people on board, that is people with high initiative and possess the right skills and competencies. When this happens, the people will help formulate good objectives and ensure the organisation's vision is achieved. The literature confirms that companies that see employees as the most valued asset and therefore acquire and keep the right calibre of employees are successful (Gabčanová, 2011). It should however be noted that not all people are valued assets of an organisation but the right people are the valued asset. When the right people are acquired then one considers what should be done. In deciding on what should be done, it is important to consider the needs of the residents affiliated to tourism who, Woo et al. (2018), describe as government officials, business leaders and other community residents employed in the tourism sector. These people should perceive the tourism industry to have a positive impact on their leisure and social wellbeing. This is so because those affiliated with tourism are more likely to support the development of tourism in their community to enhance the community's tourism competitiveness (Woo et al., 2018).

The next is to confront the true facts. Here the idea is that there will always be difficulties but the difference is one's ability to face those challenges and address them. Organisations should have the discipline to confront challenges regardless of the difficulties. The next characteristic is what Collins (2001) describes as the Hedgehog concept. The Hedgehog concept reflects the understanding about the intersection of three circles which are: understanding what you can (and cannot) be best at; what you are deeply passionate about; and what drives your economic engine. Hence, for tourist sites to achieve sustainable competitive advantage, its leaders need to understand the passions of the organisation, that is, know what the people are deeply passionate about. This is so because employee perform when they have positive job attitudes such as work passion (Astakhova and Porter, 2015; Kim et al., 2015). Aside this, it is important to know the drivers of the economy, that is, know what drives profitability for their business. Within the tourism industry hotels affiliated to an international chain, hotels operating under a franchise contract, attractive tourist region and the hotels located in coastal or scenic areas have a better chance of being profitable (Sami and Mohamed, 2014). Lastly, understand where they can be (or cannot be) the best in the world. The organisation should simply stick to doing what they do best and avoid being detracted from their core business into new areas that may not be their speciality and therefore lack the required competencies.

A culture of discipline is the next characteristic and according to Collins (2001), organisations that have lesser degree of competences and lack discipline result in 
bureaucratic culture. A culture of discipline within an organisation is about getting disciplined employees who are involved in disciplined thoughts and who will take disciplined actions. When organisations have disciplined employees, it eliminates the need for bureaucracy and not much need for excessive control (Collins, 2001). Thus, for tourist sites to develop a sustainable competitive advantage and move from good to great companies, it needs to have a culture of discipline where the employees will have disciplined thought and take disciplined actions.

The last strategy tourist sites can use to build sustainable competitive advantage using Collins (2001) model is to see new technology as a business accelerator. Organisations should not target any kind of technology that others are using as the main means for transformation. It should rather determine which technology is most appropriate for them and then develop unique application of these technologies to grow and enhance their business. This implies, even though the adoption of modern technology help improve performance (Imran et al. (2014), organisations should not just get caught up in the use of new technology, but adopt technology that will accelerate their performance in the area they are passionate about.

Thus, for tourist sites to build sustained competitive advantage it should aim at and ensure it has Level 5 leadership, ensure it has quality employees before deciding on what they have to do; confront the true facts; adopt the Hedgehog concept; develop culture of discipline; and lastly, use relevant technology to speed up performance.

\section{Methodology}

This study was qualitative in orientation and required the use of non-probability sampling method in selecting respondents. Consequently, purposive sampling method was used to select respondents for the study based on their ability to provide significant knowledge and information on the issue under study (Tracy, 2010; Yin, 2011). In addition to this, the study sites which are the centre for arts and culture and Kwame Nkrumah Mausoleum, were purposively chosen. This is because most visitors to Ghana buy their souvenirs ranging from carvings, prints, paintings, sculpture, beads, stools, bags etc. from centre for arts and culture, which can be described as a tourist haven in addition to its being one of the oldest state institution for culture and heritage development. The Kwame Nkrumah Mausoleum, on the other hand, attracts many tourists as it is dedicated to the memory and history of the first President of Ghana, Osagyefo Dr Kwame Nkrumah, who was once voted the most influential African in a century. Mausoleums, alternative type of memorial, are built as free-standing monuments in which the remains of the deceased are kept. The literature outlines different reasons why people visit mausoleums and cemeteries. Without empirical research Seaton and Lennon (2004) suggested one such reason as the need to pay tribute to significant others, public or personal. Nordh et al. (2017) added that, people visited mausoleums and cemeteries to relax and move away from stresses of daily life, reflect and be alone. The Kwame Nkrumah Mausoleum and memorial park fulfils this criterion as it is a place dedicated to the first president of the republic of Ghana and tourists travel from far and near to see the park. Also, the mausoleum provides a destressing environment with its beautiful springs of water at the entrance and serene environs. Due to the strategic importance of mausoleums, managers have to ensure it improves on its attraction and market competitiveness and improve its cultural values, artistic values and historical values (Zhou, 2019).

The sample size for the study was twenty-three respondents; twelve males and eleven females. This sample size was based on "information power" concept as suggested Malterud et al. (2016) who argues that "information power indicates that the more information the sample holds relevant for the actual study, the lower amount of participants is needed". Thus, the number of people interviewed was not determined prior to collection of data. This is because a general sampling guideline for qualitative research is to continue sampling until no new knowledge is gained from respondents (Cooper and Schindler, 2014). That is, the suitable 
IHR

36,1

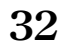

number of respondents is arrived at when responses provide no new data. This is the point of saturation. The need to reach saturation cannot be overlooked in qualitative studies because failure to reach data saturation has a negative impact on the validity of the research (Fusch and Ness, 2015). As Faulkner and Trotter (2017, p. 2048) posited that "saturation means that a researcher can be reasonably assured that further data collection would yield similar results and serve to confirm emerging themes and conclusions". Saturation was achieved after 23 interviews, hence, the justification for our sample size.

We employed semi-structured interviews with respondents made up of mainly both local and foreign tourists, tour site employees and individual shop owners. Respondents were approached and asked if they were willing to be interviewed, thus oral consent was sought from all respondents prior to the interviews. Appointments were booked in advance where necessary and those available were interviewed on scheduled dates. Interviews were conducted for an average of thirty minutes per person and in the premises of two tourist sites. The interview guide had a combination of descriptive and opinion questions and probing questions emerged during the interview process based on the responses given. Respondents were assured of data confidentiality and anonymity as well as voluntary participation. Interviews were recorded on a digital device with the permission of participants. To ensure validity of the data, member-check was done via playing back the recorded audio file to respondents after the interview for them to validate their response (Creswell and Miller, 2000). Additionally, the reliance on data saturation aided in increasing the validity and reliability of the results of the research data (Fusch and Ness, 2015).

The recorded interviews were transcribed after which we read all the transcripts severally to familiarise ourselves with the issues and emerging themes (Saldaña, 2013; Tracy, 2010). Through a line-by-line coding process, we create modified and fine-tuned codes that had been created during the data collection process. This “interactive art” (Saldaña, 2013, p. 4) of coding required us to make meaning of issues in the transcripts and come up with words or phrases that capture the essence in these issues. Most of the generated codes were in vivo in nature and thus based on remarks of respondents. A code list with brief description of what each code comprises was developed. The transcripts were then imported into and coded with QSR Nvivo 11 Pro. As a qualitative data analysis and management software program, Nvivo is user-friendly, interactive and intuitive nature which allowed us not just to code and analyse rigorously but also provided us the opportunity to make notes or memos of emerging themes. Moreover "with purpose-built tools for classifying, sorting and arranging information, NVivo helps a researcher manage and organize data and facilitates the analysis of data, identification of themes, gleaning insight and developing conclusions" (Wallace et al., 2019). In addition Nvivo helped us to keep all research documents in one place making coding and analysis effective and less tiresome. Moreover, the framework matrix function in Nvivo was ideal in getting a comprehensive summary of the coded sections of the transcripts across both respondents and themes. All codes were created as nodes using the developed code list. A framework matrix, which is an excel sheet, was generated in Nvivo after all transcripts have been coded. Using this framework, comprehensive summaries of each of the themes based on the all responses was done and used in writing the findings which is discussed in the next section.

\section{Discussion of findings \\ Role of stakeholders}

Respondents mentioned that some individuals and groups play important roles in ensuring sustainable tourism in the country. In line with the research objectives, the relevant stakeholders identified were employees, government, the society/community and the private sector. 


\section{Employees}

The success of organisation depends much on the employees who work there. Findings from the data show that employees play a major role towards the success of the tourism industry. When employees ensure that the environment of the tourist site is clean, safe and welcoming, it attracts more tourists and ensures its sustenance. This is because tourists see security and safety as very important and contribute towards their satisfaction level (Alananzeh, 2017). Majority of the respondents raised this point, for instance, one respondent remarked that

we need to protect the customers who come here from the many hawkers around which sometimes deters people from coming. This place should be very welcoming to visitors in order to attract more people here.

Another respondent added that "the sites have to be always safe and everything is clean and the tourist have access to it". This implies that when employees ensure that the tourist site is clean and safe it draws tourists to the site and thus ensures it is sustainable. Another finding from the study that is linked to this is the need for Ghanaians to cherish what they have and also make efforts in preserving it. This is based on the assumption that ones the citizenry cherishes what they have all efforts will be made to ensure that it is safe and welcoming "The thing is that we must cherish want we have as Ghanaians and make the effort to preserve it".

\section{Government}

Regardless of the level of development of the tourism industry in a country, government is a major stakeholder and therefore plays significant role. Cultural heritage is recognised as one of the major contributors to the economy and has traditionally been funded from the public sector. Operating in an increasingly competitive tourism environment, museums have moved away from their traditional role as collectors and conservators of artefacts of historical importance, to become more audience-focused visitor attractions' (Easson and Leask, 2020). Results from our data shows that government plays several roles within the tourism industry although the chief role that all respondents mentioned was the provision of infrastructure and financial support. Other roles identified include educating the populace/advertise and provision of directional signs.

Tourism infrastructure has been cited as the basis for tourism development (Jovanović and Ivana, 2016). Governments have a responsibility to collaborate with the citizenry to provide adequate infrastructure for the tourism industry. This need for collaboration confirms what the stakeholder theory states. The theory espouse that organisations and other stakeholder need to work hand in hand. A respondent noted that:

They have to sit together and discuss how they can attract tourist from elsewhere and help this population to building infrastructure which are necessary. So that the government can help them not to give them money but to build what is necessary, build roads which is also open during the raining seasons.

In addition, the government has to educate the populace on tourism and advertise to help boost tourism. For instance, a respondent stated that:

The government should advertise more so that those outside the country will know the good work we are doing here. If this happens and we are also producing quality goods more tourist will be attracted to come to our country to see the good things we have.

Another role that the government is expected to play is the provision of financial resources to maintain these sites. Discussions with employees and managers of the two tourist sites revealed that financial constraints often hinder the abilities of these sites to provide attractive services to tourist who come visiting. For some employees and managers, although the
Stakeholder role in tourism sustainability 
IHR

36,1

\section{4}

government is providing financial assistance, it is often not adequate to meet the needs of the sites. For instance, a manager of one of the sites remarked that

We get funding but not enough funding. I must admit that the current government is trying to promote all the tourist attractions in the country so now it is improving. So funding is coming but not as we expected but compared to previous years, it is better. So we hope it continues because if it does we are going to see a lot of change in the tourism sector.

\section{Community/society}

Another stakeholder identified was the community or society within which the tourist site is located. Ghanaians within these communities are expected to be proud of the sites and collaborate with others to ensure the sustainability of the sites. It was suggested that "we cherish what we have as Ghanaians and make the effort to preserve it". Again, when individuals in the society ensure that their surroundings are clean and hygienic and provide a welcoming environment, it will serve as a pull factor that will draw tourist in these communities.

\section{Private sector}

From the findings, the respondents believe that most of the people who are into art have raw talent and normally need training and guidance to produce quality products that can meet international standards. Some of the respondent mentioned that they usually get support from Japanese and German agencies to organise trainings to help the youth nurture their talent and produce pictures, carvings and the others that will meet international standards. Respondents suggested that there is the need for the government to partner with private agencies who are often the promoters of tourism in the country due to the fact that they are the ones who run the hotels, restaurants, shops, tour companies etc. getting the private sector fully involved in promoting tourism will go a long way to ensure sustainable tourism in the country.

\section{Individual shop owners}

Although shop owners who sell souvenirs often interact with tourist, the study revealed that a good number of these shop owners only know what respondents' call "sale English". They are often uneducated or illiterates who can hardly understand the dynamics of the market. Most of these shop owners are exploited and they unable to fight for their rights. Respondents believe that when shop owners are more abreast with new ways of managing their resources and providing services, it will go a long way to ensure sustainable tourism.

The study also revealed that Ghanaians do not encourage domestic tourism so people should learn how to promote tourism in the country. Also, the new generation and upcoming youth must be educated on the importance of tourism. They also mentioned that the country has artist that can promote our culture who are rich in terms of visual arts and paintings but they cannot be promoted but the lives of these artist do not encourage the young ones who are naturally gifted with the arts to undertake the arts courses even in secondary schools. Respondents recommended that the state should have a national art centre that suits international standards and which exposes shop owners to new ways of working.

\section{Challenges of the tourism industry}

Due to the rapid booming of the tourism industry, it experiences constant changes, which come with challenges. Findings from this study revealed some challenges within the tourism industry. The high level of illiteracy among shop owners and craftsmen providing product to 
tourist, the lack of domestic tourism, little or non-involvement of the youth in tourism, lack of publicity of tourist sites in the country, poor maintenance culture, insufficient governmental support in creating an enabling environment, lack or inadequate funding, lack of law/authority or enforcement of the laws to prevent copying/imitation and low patronage of tourist sites are some of the challenges that respondents outlined. Another challenge that providers of artefacts mentioned was that the poor perception that people have about those who produce and craft artefacts. Due to this perception, the youth are especially demotivated to go into the production of artefacts for sale at tourist sites. These findings support the suggestion made by Siakwah et al. (2019) that "there is a need for collaboration between governments, institutions, international actors, CSOs and locals to promote governance based on justice, inclusion, trust, and equitable power relations. Local communities must become genuine partners in sustainable tourism governance in Africa”.

\section{Ensuring sustainable tourism - competitive advantage}

Tourism is a major source of employment and income and therefore there is a need to sustain it. Our findings show that several factors can contribute to sustainable tourism and competitive advantage. For instance, the Kwame Nkrumah Mausoleum is a museum dedicated to one person and as such everything displayed there is unique, valuable and cannot be measured. Its uniqueness also means that although certain things related to the first president can be found online and at other sources, the products at the museum are not available at other sources and thus they cannot be imitated and substituted.

This is however not the case at the art canter where respondents complained that most of their products, though valuable, can be found at market places like Osu, Makola markets and even airport, but the quality products can only be found at the arts centre. They therefore recommended that more advertisement is done for both tourists and locals to come to the art centre for valuable and quality products. Studies done by Preko et al. (2020) pointed out that tourist experience affects satisfaction and therefore revisit to tourist sites. This means that product quality at the tourist site can affect satisfaction of tourist and hence their revisit or recommendation. Also the government needs to get in touch with travelling agencies around the world to promote the tourism sector because there are many people interested in coming to Ghana but they lack information as well as they do not hear positive things about the country as well as Africa.

Respondents added that education and awareness creation of tourist sites within the country particularly to locals will enhance domestic tourism as well as ensure sustainability of these sites. One fascinating idea that respondents mentioned in this regard is the use of sign boards and foot markings along the street to provide directions to the tourist sites as done in other places around the world. This, respondents mentioned, will make it easy for people to know the existence of these sites, which are sometimes very difficult to find. Other respondents, especially locals remarked that there is a need to educate the children and youth about the importance and relevance of tourism.

Thus, there is a need to ensure that the knowledge about tourism is sustained as one respondent remarked "yes they are. Knowledge is valuable and it cannot be measured". If the tourism industry can be sustained people should be educated about the history of the industry, the various sites, so they can share the uniqueness of the site. When these unique characteristics are shared and its value publicised it will draw more people to the site and thus sustained.

Again, most of the respondents proposed that the product at the tourist sites should be valuable to help ensure sustainable tourism. The literature support that value is created through museum tourism (MT) through cross-cultural understanding in communities and society, as a recreation resource and education (Calinao and Lin, 2017; Pennings, 2015; Sandahl, 2019). A valuable product according to Madhani (2010) provides strategic value to 
IHR

36,1

the firm and therefore the society. For example, the African Arts Museum in the Republic of Korea displays African artefacts like statues and wildlife from the 18th to 20th century giving tourists a feel of the African culture and hence can help those who admire African heritage issues to keep visiting the museum. When the products are unique it provides this strategic value for the organisation. The uniqueness is also seen in the natural environment available.

Again, to ensure sustainable tourism one should ensure the product is rare. Rare products are those that existing and potential competitors find it difficult to discover (Madhani, 2010). As a result of the difficulty to find, tourists are attracted to visit such sites and thus ensure the site's sustainability. An interviewee confirmed this when he said

... the pictures here are rare and people are not allowed to take pictures of them. People are not allowed to take pictures of the collections in the museum but they can do so outside of the museum. So the collections we have in there cannot be acquired from anywhere.

Ensuring that the product offered cannot be substituted is another way to ensure sustainable tourism. Again, it was also found that when a product is not imitable it helps sustain the tourism industry. Non-imitable products are those that making a copy or imitating it is not feasible. While some confirm their products are non-imitable others says the products can be imitated by competitors.

Respondents also noted that there is a need for tourist managers to embark on aggressive marketing strategies that puts participants first. Such strategies could give promotional packages in tourists and create healthy competition and collaboration among tourist sites in the country. These strategies can be best designed if management is able to project the profiles of potential clients to these sites. This can be done via studying and analysing the profile of previous clients. This finding echoes Kara and Mkwizu (2020) assertion that demographic factors such as age, gender and family size significantly influenced travel motivation for both local and international leisure tourists in Tanzania. This findings, can guide future studies to verify how this can affect promotional packages by stakeholder firms for local and foreign tourists in Africa. Moreover, encouraging regular feedback from tourists would help in shaping future policies and marketing strategies.

Access to relevant information was another factor that was identified. Relevant information at websites can ensure tourists are well informed to decide on places to visit among others. Thus the use of digital marketing strategies particularly on social media can go a long way to advertise these sites to the world. Respondents suggested that local authorities and site management can partner with radio stations so as to get a platform to advertise these sites to boost both international and domestic tourism.

Others mentioned keeping a clean environment, regular maintenance of the sites, promoting the products and maintain standards. The Table 1 below provides a matrix summary of the findings from the study.

\section{Theoretical implications}

The study filled important contextual gaps in the literature via focussing on the Ghanaian context of stakeholder participation in tourism development by focussing on two popular tourism sites in the city of Accra. Although previous studies have discussed the contribution of stakeholders to tourism development in Europe and other advanced economies, there has remained a lack of research into stakeholder theory and combination with resource based view theory application in Ghana as well as from the context of African tourism and hospitality industry. The use of the RBT and Stakeholder theory in this study underscores the importance of effective use of limited resources by both government and private sector operators to enhance tourism sustainability in the developing country. . The findings indicate that all stakeholders can come together to build sustainability in the tourism industry. 


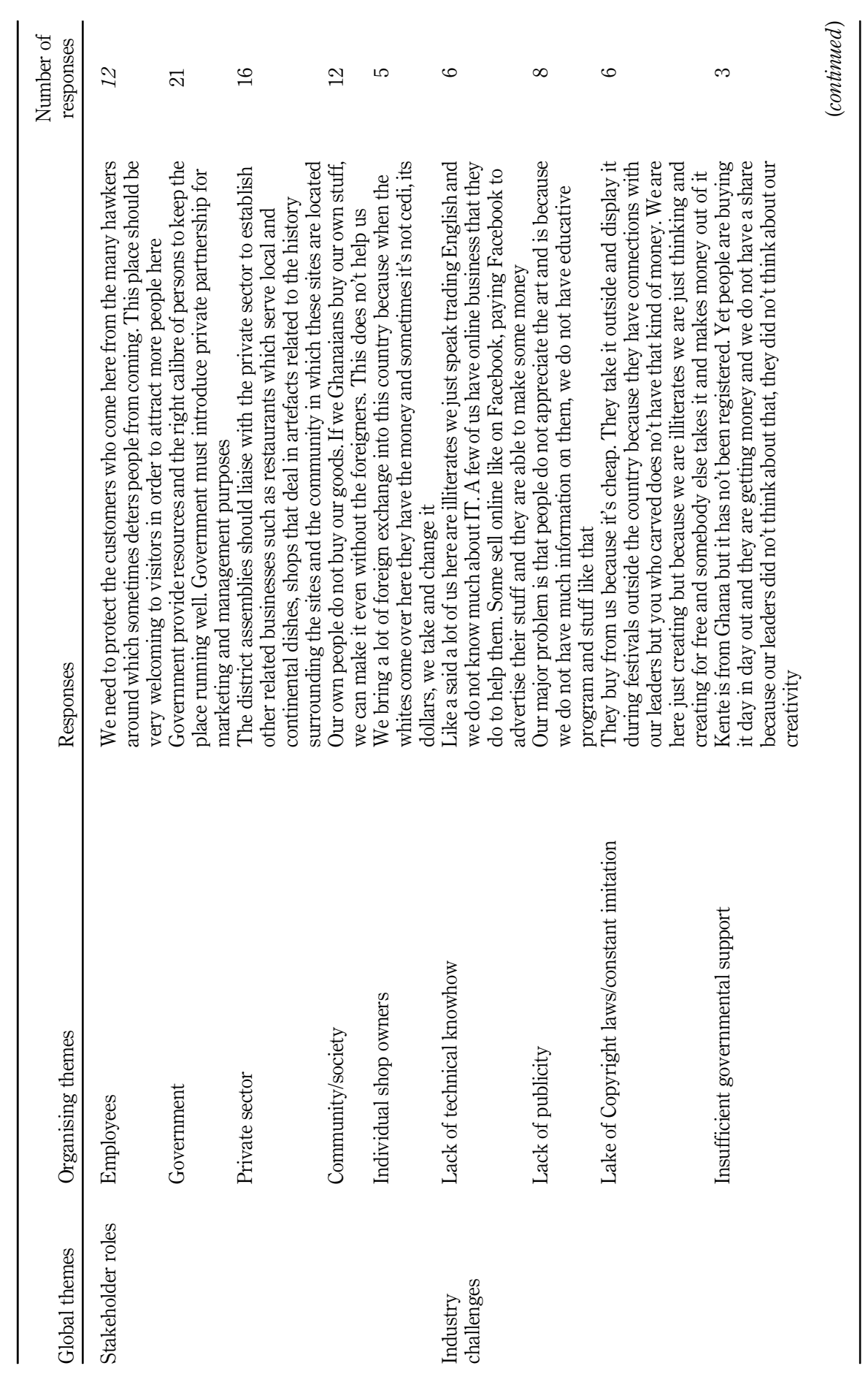

Stakeholder role in tourism sustainability

Table 1 .

Summary matrix of findings 


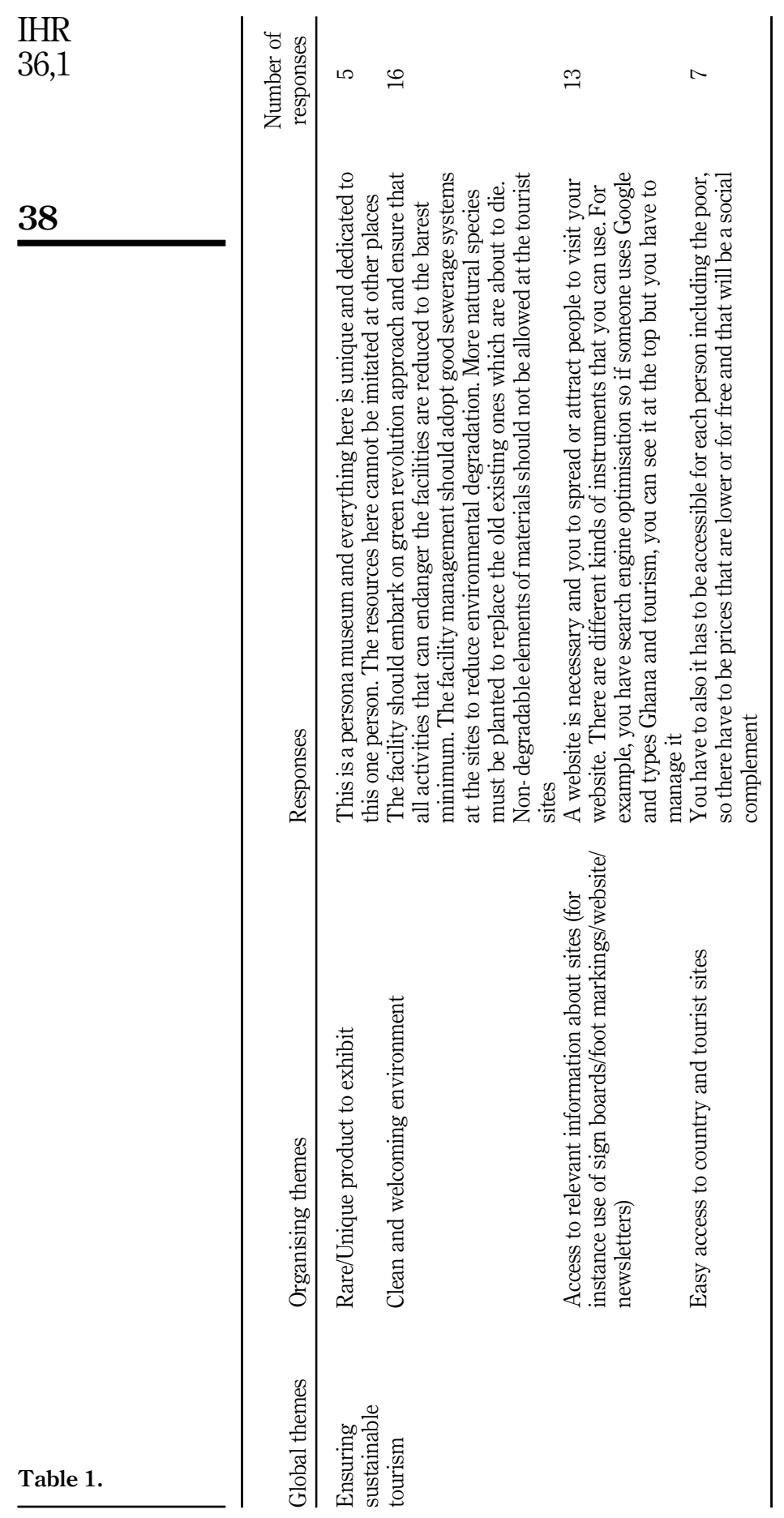


Tour operators in Malaysia for example are reported to have adopted sustainable tourism practices in their daily operations and they readily implement these practices as their sustainable business management strategies (Hamid and Isa, 2018). This study also identified that, the adoption of sustainable tourism practices is a potential effective business strategy for tour operators in Ghana based on the feedback from respondents.

\section{Managerial implications}

The study provided useful and practical prompts for policy makers, tourists and government and private tourism service providers. Most notably, they must focus on training their employees to provide exceptional interactions with both local and foreign tourists. Poor infrastructure, financial challenges and the lack of education and training came up as some of the main challenges facing the tourism industry in Ghana. This finding is a pointer to the need for government and public institutions to provide basic infrastructure so that investors and stakeholders in the tourism industry can do better. Operators in the industry will have to invest in capacity building for their staff so they can deliver better customer service to visitors. Information and sign post leading to tourist attractions is some identified problems that managers of service providers can easily resolve. Moreover, in order to attract more tourist service providers must provide quality goods and services in a clean and hygienic environment. Further, Ottenbacher et al. (2019) suggested that sustainability efforts are primarily driven by internal beliefs as well as behaviours of customers themselves rather than by the mere actions of firms. This means that customer education is necessary for achieving sustainable tourism goals. "The hospitality industry creates a distinctive context in which learning takes place. The industry's international perspective and large globalisation play an important role in learning, as well as the operational and structural features that give meaning to learning and development in the hospitality industry Kleefstra et al. (2020). Managers will have be aware of this learning context to develop suitable training program for employees to deliver better service. This means that customer education is necessary for achieving sustainable tourism goals. Furthermore, Chan and Xin (2015) on responsible behaviour by tour operators at Kinabalu Park in Malaysia highlighted that tour operators" play important roles in ecological and economic management as well as social and destination management.in tourism business. This implies that stakeholders must first develop the sustainability culture in their settings before external parties come on board. Thus, there is a need to appreciate the fact that no individual stakeholder's efforts is enough to achieve sustainability tourism goals but rather a blending of efforts of all stakeholders is needed to meet sustainable tourism goals. Research by Mkwizu (2020) revealed that "digital media, content and mobile advertising are among the trends in digital marketing and, thus, affords Africa the opportunity to market its attractions to tourists in this digital era". Policy makers can take advantage of this knowledge bring stakeholders together to build common digital platforms to promote their common interest.

\section{Limitations and direction for future research}

Although this study came up with several fascinating outcomes, there are a few limitations that need to be contemplated upon especially regarding interpretation and generalisation of the results. The use of a qualitative research approach and the small sample size means that the results of the study can be limited to the respondents sampled and cannot be regarded as the opinions of all tourists, although they raised very vital issues regarding sustainable tourism. In future studies could use quantitative methodological approach to make findings more applicable. Moreover, our respondents were mostly Ghanaians who do not patronise tourism well. Greater percentage of the sample taken from other countries with a different culture and lifestyle could prove to be interesting. This research is destination-
Stakeholder role in tourism sustainability 
IHR

36,1

specific hence application of the findings to other tourist sites will not be very appropriate. It will also be interesting to apply the customer pyramid theory (as used by Kozak and Martin (2012)) to investigate the profitability of tourism operators in Ghana

\section{Conclusion}

The conclusion of this study is that the challenges in the tourism industry in Ghana are many. Government must take the lead in providing basic infrastructure like roads, water, electricity, security to encourage stakeholders to invest in the sector. However, all stakeholders must work on their businesses to develop competitive advantage to build a vibrant and sustainable tourism industry. Sustainable tourism is an upcoming significant practice in the tourism industry. Tour operators are encouraged to participate in sustainable tourism according to their respective roles in the business' (Hamid et al., 2020). Aside the variables Madhani (2010) outlined which are valuable, rare, imitable and non-substitutable, it was found that access to relevant information plays a major role towards sustainable tourism. Thus, to ensure sustainable tourism the product should not just be valuable, rare, imitable and non-substitutable but also relevant information about the product should be readily available. At the same time individual stakeholders must develop unique competitive advantage to remain profitable. Every stakeholder must make use of the various digital and online platforms to communicate and promote their businesses. Finally, due to the current COVID-19 challenges, encouraging domestic tourism will be vital in maintaining the business sustainability of the stakeholders in this industry.

\section{References}

Alananzeh, O.A. (2017), "Impact of safety issues and hygiene perceptions on customer satisfaction: a case study of four and five star hotels in Aqaba", Jordan. Journal of Tourism Research and Hospitality, Vol. 6 No. 1, pp. 1-7.

Amit, R. and Schoemaker, P.J. (1993), "Strategic assets and organizational rent", Strategic Management Journal, Vol. 14 No. 1, pp. 33-46.

Astakhova, M.N. and Porter, G. (2015), "Understanding the work passion-performance relationship: the mediating role of organizational identification and moderating role of fit at work", Human Relations, Vol. 68 No. 8, pp. 1315-1346.

Barney, P. (1991), "Firms resources and sustained competitive advantage", Journal of Management, Vol. 17 No. 1, pp. 99-120.

Boachie, W.K. (2012), "Assessing sustainable development in the mining industry in Ghana: a question of corporate perspective", Journal of Economic and Sustainable Development, Vol. 3 No. 10, pp. 113-119.

Bowman, C. and Ambrosini, V. (2000), "Value creation versus value capture: towards a coherent definition of value in strategy", British Journal of Management, Vol. 11 No. 1, pp. 1-15.

Bramwell, B., Lane, B., McCabe, S., Mosedale, J. and Scarles, C. (2008), "Research perspectives on responsible tourism”, Journal of Sustainable Tourism, Vol. 16 No. 3, pp. 253-364.

Butler, R.W. (1999), "Sustainable tourism: a state-of-the-art review", Tourism Geographies, Vol. 1 No. 1, pp. 7-25.

Byrd, E.T. (2007), "Stakeholders in sustainable tourism development and their roles: applying stakeholder theory to sustainable tourism development", Tourism Review, Vol. 62 No. 2, pp. 6-13, doi: 10.1108/16605370780000309.

Calinao, D.J. and Lin, H.W. (2017), "The cultural tourism potential of a fashion-related exhibition-the case of Alexander McQueen: Savage Beauty at the Victoria and Albert Museum”, Journal of Heritage Tourism, Vol. 12 No. 2, pp. 204-217. 
Chan, J.K.L. and Xin, T.K. (2015), "Exploring definitions and practices of responsible tourism in Kinabalu National Park, Sabah, Malaysia”, Journal of Tourism and Hospitality Management, Vol. 3 Nos 5-6, pp. 87-101.

Collins, J. (2001), Good to Great, Harper Business, New York, NY.

Cooper, R.D. and Schindler, P.S. (2014), Business Research Methods, 12th ed., McGraw-Hill Company, Boston.

Creswell, J.W. and Miller, D.L. (2000), "Determining validity in qualitative inquiry”, Theory into Practice, Vol. 39 No. 3, pp. 124-130.

Davis, P.J. and Simpson, E. (2017), "Resource-based theory, competition and staff differentiation in Africa: leveraging employees as a source of sustained competitive advantage", American Journal of Management, Vol. 17 No. 1, pp. 19-33.

Della, B.M., Liu, R., Ravarini, A., Wu, F.Y. and Nigam, A. (2012), "Sustained competitive advantage using business entities (SCUBE): a practical approach for business agility", Information Systems: Crossroads for Organization, Management, Accounting and Engineering, Physica, Heidelberg, pp. 11-18.

Domfeh, K.A., Ahenkan, A. and Bawole, J.N. (2012), "Is sustainable achievable in Ghana? An analysis of Ghana's development policy achievement ad challenges", International Journal of Environment and Sustainable Development, Vol. 11 No. 3, pp. 304-317.

Donaldson, T. and Preston, L.E. (1995), "The stakeholder theory of the corporation: concepts, evidence and implications", Academy of Management Review, Vol. 20 No. 1, pp. 65-91, doi: 10.5465/AMR. 1995.9503271992.

Easson, H. and Leask, A. (2020), "After-hours events at the National Museum of Scotland: a product for attracting, engaging and retaining new museum audiences?", Current Issues in Tourism, Vol. 23 No. 11, pp. 1343-1356.

Fahy, J. (2000), "The resource-based view of the firm: some stumbling-blocks on the road to understanding sustainable competitive advantage", Journal of European Industrial Training, Vol. 24 Nos 2/3/4, pp. 94-104.

Faulkner, S.L. and Trotter, S.P. (2017), "Data saturation”, in Matthes, J., Davis, C.S. and Potter, R.F. (Eds), The International Encyclopaedia of Communication Research Methods, John Wiley \& Sons, Hoboken, New Jersey, NJ, p. 2048.

Freeman, E. (1984), Strategic Management: A Stakeholder Approach, Pitman, Toronto.

Fusch, P.I. and Ness, L.R. (2015), "Are we there yet? Data saturation in qualitative research", The Qualitative Report, Vol. 20 No. 9, pp. 1408-1416.

Gabčanová, I.V.E.T.A. (2011), "The employees-the most important asset in the organizations", Human Resources Management and Ergonomics, Vol. 5 No. 1, pp. 30-33.

Goeldner, R. and Ritchie, B. (2005), Tourism: Principles, Practices, Philosophies, 9th ed., John Wiley \& Sons, Hoboken, NJ.

Hamid, M.A. and Isa, S.M. (2018), "The Influence of adopting sustainable tourism practices towards sustainable performance among Malaysian tour operators", 6th Interdisciplinary Tourism Research Conference, 2-7 October 2018, Avanos, Nevşehir, Turkey, Proceedings Book 169.

Hamid, M.A., Isa, S.M. and Kiumarsi, S. (2020), "Sustainable tourism practices and business performance from the tour operatorsâ perspectives", Anatolia, pp. 1-10, doi: 10.1080/13032917.2020.1830135.

Harrison, J.S., Freeman, R.E. and Abreu, M.C.S.D. (2015), "Stakeholder theory as an ethical approach to effective management: applying the theory to multiple contexts", Review of Business Management, Vol. 17 No. 55, pp. 858-869.

Higgins-Desbiolles, F., Carnicelli, S., Krolikowski, C., Wijesinghe, G. and Boluk, K. (2019), "Degrowing tourism: rethinking tourism", Journal of Sustainable Tourism, Vol. 27 No. 12, pp. 1926-1944.

Hopwood, B., Mellor, M. and O'Brien (2005), "Sustainable development: mapping different approaches”, Sustainable Development, Vol. 13, pp. 38-52. 
IHR

36,1

Imran, M., Maqbool, N. and Shafique, H. (2014), "Impact of technological advancement on employee performance in banking sector", International Journal of Human Resource Studies, Vol. 4 No. 1, pp. 57-70.

International Council for Metals and Mining (ICMM) (2012), Mining Contribution to Sustainable Development, ICMM, London, available at: https:/www.icmm. com/website/publications/pdfs/ 3716.pdf.

Jovanović, S. and Ivana, I.L.I.Ć. (2016), "Infrastructure as important determinant of tourism development in the countries of Southeast Europe”, Ecoforum Journal, Vol. 5 No. 1, pp. 288-294.

Kara, N.S. and Mkwizu, K.H. (2020), "Demographic factors and travel motivation among leisure tourists in Tanzania", International Hospitality Review, Vol. 34 No. 1, pp. 81-103.

Kim, J., Nimon, K., Song, J.H. and Zigarmi, D. (2015), "Toward employee work passion and performance: a validation of the work cognition inventory in Korea", Human Resource Development International, Vol. 18 No. 2, pp. 169-190.

Kleefstra, A., Altan, M. and Stoffers, J. (2020), "Workplace learning and organisational performance in the hospitality industry", International Hospitality Review. doi: 10.1108/IHR-12-2019-0025.

Korstanje, M. and George, B. (2020), "5 Demarketing overtourism”, Overtourism and Tourism Education: A Strategy for Sustainable Tourism Futures, p. 81.

Kozak, M. and Martin, D. (2012), "Tourism life cycle and sustainability analysis: profit-focused strategies for mature destinations", Tourism Management, Vol. 33 No. 1, pp. 188-194.

Link BC (2008), "Transforming communities through tourism: a handbook for community tourism champions", [PDF] available at: http://linkbc.ca/siteFiles/85/files/TCTT.pdf.

Liu, Y.A.A., Tsai, C.T., Horng, J.S. and Lee, M.H. (2010), "An initial inquiry of program evaluation framework for tourism higher education in Taiwan", Journal of Teaching in Travel and Tourism, Vol. 10 No. 1, pp. 1-21.

Madhani, P.M. (2010), "Resource based view (RBV) of competitive advantage: an overview", available at: http://ssrn.com/abstract=1578704 (accessed 4th September 2018).

Malterud, K., Siersma, V.D. and Guassora, A.D. (2016), "Sample size in qualitative interview studies: guided by information power", Qualitative Health Research, Vol. 26 No. 13, pp. 1753-1760.

Mkwizu, K.H. (2020), "Digital marketing and tourism: opportunities for Africa", International Hospitality Review, Vol. 34 No. 1, pp. 5-12.

Musavengane, R., Tantoh, H.B. and Simatele, D. (2019), "A comparative analysis of collaborative environmental management of natural resources in Sub-Saharan Africa: a study of Cameroon and South Africa”, Journal of Asian and African Studies, Vol. 54 No. 4, pp. 512-532.

Musavengane, R., Siakwah, P. and Leonard, L. (2020), "The nexus between tourism and urban risk: towards inclusive, safe, resilient and sustainable outdoor tourism in African cities", Journal of Outdoor Recreation and Tourism, Vol. 29, p. 100254.

Nordh, H., Evensen, K.H. and Skår, M. (2017), "A peaceful place in the city-A qualitative study of restorative components of the cemetery", Landscape and Urban Planning, Vol. 167, pp. 108-117.

Ottenbacher, M.C., Kuechle, G., Harrington, R.J. and Kim, W.H., (2019), "QSR customer sustainable behaviours and brand practice perceptions on willingness to pay a premium", International Hospitality Review, Vol. 33 No. 2, pp. 106-125.

Pennings, G. (2015), "Ethics of medical tourism", Handbook on Medical Tourism and Patient Mobility, Edward Elgar Publishing, pp. 341-349.

Phillips, R., Freeman, R.E. and Wicks, A.C. (2003), "What stakeholder theory is not", Business Ethics Quarterly, Vol. 13 No. 4, pp. 479-502.

Preko, A., Gyepi-Garbrah, T.F., Arkorful, H., Akolaa, A.A. and Quansah, F. (2020), "Museum experience and satisfaction: moderating role of visiting frequency", International Hospitality Review. 
PricewaterhouseCoopers (2017), "PwC hotels outlook: 2017-2021: South Africa - Nigeria - Mauritius Kenya - Tanzania)", available at: www.pwc.co.za/outlook (accessed 28 April 2018).

Pırnar, I. and Günlü, E. (2012), "Destination management and quality-of-life", in Uysal, M., Perdue, R. and Sirgy, M.J. (Eds), Handbook of Tourism and Quality-Of-Life Research, Springer, Dordrecht, pp. 529-545.

Robbins, S.P. and Judge, T.A. (2009), Organisational Behaviour, 13th ed., Prentice Hall, New Jersey Pearson.

Saldaña, J. (2013), The Coding Manual for Qualitative Researchers, Sage, London.

Sami, B.A. and Mohamed, G. (2014), "Determinants of tourism hotel profitability in Tunisia", Tourism and Hospitality Research, Vol. 14 No. 4, pp. 163-175.

Sandahl, J. (2019), "The museum definition as the backbone of ICOM", Museum International, Vol. 71 Nos 1-2, pp. vi-9.

Seaton, A.V. and Lennon, J.J. (2004), "Thanatourism in the early 21st century: moral panics, ulterior motives and alterior desires", in Singh, T.V. (Ed.), New Horizons in Tourism: Strange Experiences and Stranger Practices, pp. 63-82, doi: 10.1079/9780851998633.0063.

Sharpley, R. (2000), "Tourism and sustainable development: exploring the theoretical divide", Journal of Sustainable Tourism, Vol. 8 No. 1, pp. 1-19, doi: 10.1080/09669580008667346.

Siakwah, P., Musavengane, R. and Leonard, L. (2019), "Tourism governance and attainment of the sustainable development goals in Africa", Tourism Planning and Development, Vol. 17 No. 4, pp. 355-383, doi: 10.1080/21568316.2019.1600160.

Tracy, S.J. (2010), Qualitative Research Methods: Collecting Evidence, Crafting Analysis, Communicating Impact, Wiley Blackwell, West Sussex.

United Nations Environment Programme (UNEP) (2005), Making Tourism More Sustainable: A Guide for Policy Makers, United Nations Environment Programme, Division of Technology, Industry and Economics, World Tourism Organization Publications, Paris.

United Nations World Tourism Organization (2008), "Understanding tourism: basic glossary", available at: http://media.unwto.org/en/content/understanding-tourism-basic-glossary.

Wallace, A., Dollery, B. and Thi Thanh Tran, C.D. (2019), "Amalgamation in action: participant perspectives on the Armidale regional council merger process", Australian Journal of Social Issues, Vol. 54 No. 4, pp. 436-455.

World Commission on Environment and Development (WCED) (1987), Our Common Future, Oxford University Press, Oxford.

Woo, E., Uysal, M. and Sirgy, M.J. (2018), "Tourism impact and stakeholders' quality of life”, Journal of Hospitality and Tourism Research, Vol. 42 No. 2, pp. 260-286.

Yin, R.K. (2011), Qualitative Research from Start to Finish, The Guilford Press, New York, NY.

Zhou, S. (2019), "Research on optimization of mausoleum ruins tourist attractions based on IPA method-taking Western Royal Tombs of the Qing dynasty as an example", 2019 3rd International Conference on Education, Management Science and Economics (ICEMSE 2019), Atlantis Press.

\section{Further reading}

Freeman, R.E. (2010), Strategic Management: A Stakeholder Approach, Cambridge University Press, New York, NY.

Freeman, R.E., Harrison, J.S., Wicks, A.C., Parmar, B.L. and De Colle, S. (2010), Stakeholder Theory: The State of the Art, Cambridge University Press.

Harrison, J.S., Bosse, D.A. and Phillips, R.A. (2010), "Managing for stakeholders, stakeholder utility functions and competitive advantage", Strategic Management Journal, Vol. 31 No. 1, pp. 58-74. 
IHR

36,1

International council on mining and metals (2012), "In brief mining's contribution to sustainable development - an overview", available at: http://www.icmm.com/document/3716.

McCabe, S. (2005), “Who is a tourist?' A critical review”, Tourist Studies, Vol. 5 No. 1, pp. 85-106.

Olavarrieta, S. and Ellinger, A.E. (1997), "Resource-based theory and strategic logistics research", International Journal of Physical Distribution and Logistics Management, Vol. 27 Nos 9/10, pp. 559-587.

\section{Corresponding author}

George Kofi Amoako can be contacted at: gkamoako@gmail.com

For instructions on how to order reprints of this article, please visit our website: www.emeraldgrouppublishing.com/licensing/reprints.htm Or contact us for further details: permissions@emeraldinsight.com 